\title{
Health status of working children in Jordan: Comparison between working and nonworking children at schools and industrial sites
}

\author{
Ayman M. Hamdan-Mansour ${ }^{*}$, Ekhlas Al-Gamal', Mai K. Sultan², Reema Matrouk ${ }^{3}$, \\ Maram Al Nawaiseh ${ }^{3}$ \\ ${ }^{1}$ Department of Community Health Nursing, Faculty of Nursing, The University of Jordan, Amman, Jordan \\ ${ }^{2}$ The National Council for Family Affairs, Amman, Jordan \\ ${ }^{3}$ Al-Bashir Hospital, Ministry of Health, Amman, Jordan \\ Email: ${ }^{*}$ a.mansour@ju.edu.jo, e.algamal@ju.edu.jo, mai@ncfa.org.jo, rmatrook@yahoo.com, m.nawayseh@hotmail.com
}

Received 22 January 2013; revised 24 February 2013; accepted 2 March 2013

\begin{abstract}
The purpose of this study is to explore the psychosocial and physical health impact of child labor and in Jordan and compare between working and nonworking children at schools and industrial sites. Methods: A sample of 4008 children at schools and industrial sites answered the self-report questionnaires that include physical and psychosocial health concerns, health screening survey, anger expression and child abuse survey. The results showed that both nonschool and school working children have various physical and psychosocial health problems. Physical complaints included common cold, flu, hearing and vision problems. Psychosocial ones included feeling lonely, feeling depressed, problems at home and work, and high level of anger expression, smoking cigarettes and using drugs. The study's implications for health, education, counseling, and research interventions were discussed.
\end{abstract}

Keywords: Child Labor; School Children; Psychosocial Health; Child Abuse; Physical Health; Jordan

\section{INTRODUCTION}

The phenomenon of child labor is one of the socio-economic dilemmas that has serious and negative impact on the society, in general, and on children in particular [1]. The International Labor Organization (ILO) estimated that there are at least 351.7 million working children around the world, and an important part of them are engaged in activities that have negative impact on their health and development [1]. In Jordan, the Department of Statistics (DOS) reported that in Jordan there are 32,676 working

\footnotetext{
"Corresponding author.
}

children (about $1.5 \%$ of the total children population in Jordan) [2]. One of the key arguments against child labor is that work deprives children from right to education and this will results in limiting children's future options [3]. Working children have specific characteristics such as inexperience and lack of physical and emotional maturity. Working children are also vulnerable to hazards due to their inability to recognize and assess potential risks and making appropriate decisions [4]. The literature provides evidences that working children are subject to a number of physical health problems such as physical injuries, burns, vision and hearing problems, and infectious diseases (e.g., [5,6]). According to Woodhead [3], physical problems such as injuries may lead to serious permanent disability that negatively affecting the child psychologically, and may lead to isolation and feeling of powerlessness. Previous studies also showed that working children suffer emotional abuse and neglect, peer problems, coping problem, social isolation, and substance abuse [3,5,7]. Psychologically, the literature showed that working children have low adaptive skill, have low level of physical health, smoke cigarettes, use alcohol and inhalants [8,9].

The literature, in general, asserts that child labor is a widespread problem in the world today. Unacceptable forms of exploitation of children at work exist and persist, but they are particularly difficult to research due to their hidden, sometimes illegal or even criminal nature [1]. In many situations, child workers jeopardize their health, their normal development, and even their lives. Working children appeared to have mood disorders, anxiety, stress and psychological problems more than non-working [10].

Worldwide, there is need to increase the knowledge related to psychosocial and physical health aspects of child labor. Despite the multitude of risk factors involved in child labor, there has been limited research that inves- 
tigates their psychosocial health status. Particularity, limited information available in regards to differences in psychosocial and physical health status between working and nonworking children at school and those dropped school. Addressing health status of working children at schools and those dropped schools will allow for better evaluation of the impact of child labor. This will be essential information to reform policy and public health practice and laws. Therefore, this study aimed at exploring the psychosocial and physical health impact child labor in Jordan, and compare between working and nonworking children at schools and industrial sites. The specific aims were to:

1) Identify the psychosocial and physical health impact of child labor in Jordan and compare between working and nonworking children at schools and Industrial sites

2) Indentify the differences between nonschool working children, school working children, and school nonworking children in relation to selected demographic characteristics.

\section{METHODS}

\subsection{Design}

This study utilized a descriptive, comparative, crosssectional design. Data collected using self reported questionnaire. Structured interview conducted to collect data in regards to physical and psychosocial health complaints and concerns and anger expression.

\subsection{Participants}

In this national study, there were three samples; working children who left schools, working children and still at school, and nonworking children at schools. A total of 4008 children were recruited from the five main governorates in Jordan. The target age was children at aged of 6 - 16 years old. The nonschool working sample of children was recruited using convenience sampling techniques, and has been targeted at shops, garages, streets, and industrial foci. Schools served as the source for the sample of school working and nonworking children. Schools have been selected randomly through the directorate of the Ministry of Education. The school social worker served as liaison to approach children. The inclusion criteria for children were: 1) aged 6 - 16 years at the time of interview. For working children whether at school or left school, an additional inclusion criteria was: child have a self-paid or employed by others with or without payment.

\subsection{Data Collection}

This study highlights many ethical issues, to ensure that children's' rights were not breached. Prior data collection, ethical approval was obtained from ethical and research committees at the national council for family affairs and the targeted institutions namely Ministry of Labor, Ministry of Health, Ministry of Education, and the Ministry of Social Development. After obtaining the approval, a two-stage cross-sectional survey was conducted. First, and to recruit school children, schools have been chosen randomly through the directorate of ministry of education in Jordan. A briefing session was held to introduce the study and its objectives, explain the inclusion criteria for children, together with the parents' information sheet, and the process of data collection were discussed with the school principal or/and counselors who have served as liaison to facilitate recruiting children. The school principal or counselors helped with introducing the study to the children, and sending the invitation letter to parents. Each parent was given a copy of the consent form, parent's information sheet, and a covering letter together with the name and phone number of the ethics committee and the principal investigator in the event that they have any question. Parents were asked to sign the consent form that they agree to have their children participate in the study. The written consent was sought ensuring confidentiality of the collected information before interviewing the child. Then, students were randomly sampled from each class of the selected schools. Within grades 1 - 10 (ages 6 - 16) of each school, a random sample of 20 children from each grade was randomly selected. Children whose parents signed the consent form were included in the study. To minimize the potential response bias, standardized techniques were employed to maintain consistency across data collection. All interviews were carried out by the trained research assistants using a structured format of self report questionnaire. Each interview lasted for approximately $30 \mathrm{~min}$. The interview contained two parts: the first part focuses on demographic data about the parents and the child. The second part involved the physical and psychosocial survey. Interviews were conducted in a quiet room at schools. School working children were identified by school principal, counselor, and by children themselves.

For nonschool working children, a convenience sampling technique was applied to recruit the sample. The foci of working children have been identified with help from the Ministry of Labor and the Ministry of Health. Once working children identified, the research team obtained the approval from employer to talk to the child, and child was given the consent letter to give to their parents/guardians that included a call for them (or at least one of them) to consent their child's participation in the study. The consent form included information related to the purpose of the study, its importance, and that the information in the study will be confidential. Also the 
cover letter ensured that the information will be used only for the scientific purposes. Those who have their parent guardian signed the consent form were only included in the study. The interview took place at the child's work setting.

\subsection{Measures}

The children were asked to respond to the two parts of the questionnaire. Part one related to demographic data that included age, gender, school grade, types of child labor if working, time spent at work, age work started, and the underlying reasons for entering the labor force. Part two related to physical and psychosocial health status of the child. For the purpose of the study, instruments were translated into Arabic language. Number of procedures was used to determine the reliability and validity of the tool. The tools were first translated into Arabic language by a research assistant and back translated into English language by another independent research assistant as described by Brislin [11] and Chapman and Carter [12]. The two English forms (the original and the translated) were compared in terms of conceptual rather than literal meaning of the items. The translator and the back translator met to examine the differences in the two forms. Pilot testing was conducted using school children $(n=30)$. The scales have been also checked for cultural variation. The measures were:

1) Health Screening Questionnaire [13] used to measure general health. The HSQ is a 21-item self-report measure of medical and surgical history; visits to health clinics, health providers, and hospital emergency, inpatient, and outpatient departments; and general health assessment. Responses for almost all questions are either yes or no, with the exception of the last question which asks, "In general, would you say your health is...," and the response ranges from excellent (1) to poor (5). The scale has good internal consistency, with a Cronbach's alpha coefficient of 0.88 . In this study, the Cronbach's alpha coefficient for the total scale was 0.83 .

2) Adolescent Health Inventory (AHI) [14] used to measure health concerns and risk behaviors. AHI is an instrument to determine the health needs and concerns of adolescents and consists of 39 questions grouped for reporting four categories: general health, psychosocial, substance abuse, and sexual behaviors. The scale has been modified to age of the sample in this study. Responses made on a Likert scale and ranges from never (0) to always (3). AHI has good internal consistency with Cronbach's Alpha ranges from 0.52 to 0.80 across categories. In this study the internal consistency had almost similar Cronbach's Alpha to those reported and ranged from 0.58 (sexual behaviors) to 0.78 (psychosocial concerns).

3) Anger Expression Scale for Children (AESC) [15] was used to measure anger. The AESC is a 26-item paper-and-pencil measure that utilizes a four-point Likert response format (almost never, sometimes, often, and almost always) with higher values keyed to greater endorsement of the items. The scale is divided into 4 domains: Anger Expression/Out, Anger In/Hostility, Anger Control/Suppression. This measure is reliable and valid and has been used with children at age 6 - 18 years. Cronbach's alpha coefficient for the total scale was 0.79 .

\subsection{Data Analysis}

The Statistical Package for Social Science (SPSS 18) software was considered as suitable software for data entry, storage and analysis. Descriptive statistical analysis such as frequency count, percentage, mean, median and standard deviation was employed to describe the research sample, in different groups. The Pearson product-moment correlation coefficient was used to describe the association between variables. ANOVA was used to compare means. Statistical significance was set at $\mathrm{p} \leq$ 0.05 .

\section{RESULTS}

\subsection{Demographic Characteristics}

A total of 4008 children aged 6 - 16 years were interviewed. The city of Amman formed the largest percentage of participants $(34.0 \%, n=1363)$, while $(19 \%, n=$ 763) of the children were from the city of Zarqa, Irbid $(15.8 \%, \mathrm{n}=634)$ children, Balqa $(12.9 \%, \mathrm{n}=516)$ children, and Ma'an $(5.5 \%, \mathrm{n}=220)$ children. Of them, 2093 (52.2\%) were nonworking school children, 896 (22.4\%) were school working children who, and 1019 (25.4\%) were nonschool working children. In regards to gender of the children, the majority of participants in the study were males $(74.8 \%, \mathrm{n}=2998)$, while female children accounted for $25.2 \%$, $(n=1010)$. Regarding the state of the working among the nonschool working, the majority of working children were males $(96.6 \%, n=984)$, while female children represented 3.4\% $(n=35)$. Regarding status of work among the school children, the majority of working children were also males $(29.4 \%, \mathrm{n}=878)$, while female school working children were only $0.006 \%$ $(n=18)$. In regards to type of work, most of the working children are generally employed in the services sector (32\%, $n=567)$, while $17.3 \%(n=307)$ of children are working in the vehicles repair, and $17.7 \%(n=314)$ of the children are working in primary vocations such as carpentry and blacksmith.

In regards to reasons for work (see Table 1), the study revealed that the majority of nonschool working children work to learn skill (43.3\%, $n=441$ children) and (36.6\%, $\mathrm{n}=369$ children, respectively). Similar results were re- 
Table 1. Reasons for work in relation to working status.

\begin{tabular}{ccccc}
\hline & \multicolumn{4}{c}{ Working status } \\
\cline { 2 - 5 } Reason for work & $\begin{array}{c}\text { Nonschool working } \\
\text { children }\end{array}$ & \multicolumn{2}{c}{$\begin{array}{c}\text { School working } \\
\text { children }\end{array}$} \\
\cline { 2 - 5 } & $\mathrm{n}$ & $\%$ & $\mathrm{n}$ & $\%$ \\
\hline Forced to work & 55 & 5.4 & 36 & 4.0 \\
Learn a skill & 441 & 43.3 & 343 & 38.2 \\
Helping family & 369 & 36.2 & 280 & 31.3 \\
Paying debts & 5 & 0.05 & 14 & 1.7 \\
Additional income & 139 & 13.6 & 193 & 21.5 \\
\hline
\end{tabular}

vealed among school working children as the main reason for work was learning a skill $(38.2 \%, \mathrm{n}=343)$ and helping family $(31.3 \%, \mathrm{n}=280)$.

\subsection{Health Screening Survey}

Concerning health problems experienced by children in this study, the results (Table 2) showed that school nonworking children had the highest reports of common colds, visiting doctor for a health problem, visiting emergency department, and admission to hospital (64.1\%, $35.5 \%, 14.3 \%, 7.6 \%$ respectively). While, nonschool working children had the highest reported incidence of influenza (27.0\%).

\subsection{Health Concerns and Risk Behaviors}

\subsubsection{Physical Health Concerns}

The study showed that 31.0\% $(n=316)$ nonschool working children had problems in teeth, and 23.9\% ( $\mathrm{n}=$ 244 children) had problems in vision, and 52.4\% ( $\mathrm{n}=$ 534) children suffering variable levels of headache, and the majority of them $(90.0 \%, \mathrm{n}=917)$ experiencing problems in hearing or enuresis. Regarding school nonworking children, the analysis showed that they do not differ much from working children in terms of health concerns and behaviors and risk factors. The results showed that about $60.0 \%(n=1256)$ of the school nonworking children have dental problems. About $17 \%(\mathrm{n}=$ 356) of them are suffering headaches most of the times, while $24.5 \%(\mathrm{n}=511)$ had problems in vision, $11.0 \%(\mathrm{n}$ $=230)$ in hearing, and 5.7\% $(n=119)$ had problem of enuresis. Reports from school working children were different their counterparts at school or out of school. The results showed that about $69.0 \%(n=618)$ of them have dental problems, $65.0 \%(\mathrm{n}=582)$ suffering headache, 33\% ( $\mathrm{n}=296)$ had vision problem, 13.1\% $(\mathrm{n}=117)$ had hearing problems, and about 5.5\% $(n=49)$ had enuresis problem.

The analysis also showed that there were significant differences between school working, nonschool working, and school nonworking children in regards to compliant of common cold, influenza, and checking doctors for health problem. As mentioned school nonworking children were the most to report compliant of common cold and checking doctors for health problem, while nonschool working children were the most the report influenza.

\subsubsection{Psychosocial Health Concerns}

Regarding the psychological and social concerns, the analysis showed that there was significant number of nonschool working children suffering from psychologycal and social problems (see Table 3). The study showed that $24.1 \%(n=242)$ of them suffer from the loneliness, $26.9 \%(n=271)$ from depressed feeling, 35.8\% $(n=359)$ problems at home, $23.7 \%(n=237)$ problems with the employer, $13.7 \%(n=137)$ problems with the law, and about $43.2 \%(n=463)$ spend most of their time alone. However, $87 \%(n=780)$ of the children reported that they have intimate friends that are considered as a positive indicator for social wellbeing.

Regarding psychological and social concerns of school nonworking children, the analysis (Table 3 ) showed that about 32.8\% $(\mathrm{n}=672)$ of children suffering loneliness and $30.9 \%(n=631)$ have problems at home, and $26.6 \%$ $(n=545)$ have problems in schools. In addition, about $89 \%(n=1863)$ of the children reported that they have an intimate friend.

Regarding psychological and social concerns of school working children, the analysis (Table 3) showed that about 39.9\% ( $\mathrm{n}=378)$ of children feel lonely, and 36.5\% $(\mathrm{n}=318)$ reported that they have depressed feeling, and $38.3 \%(n=332)$ suffered from problems at home. Also about $89 \%(n=797)$ of children reported that they have intimate friend.

\subsubsection{Risk Behaviors}

Related to risk behaviors, the general reports of the nonschool working children were variable (Table 3 ). The analysis showed that $43.4 \%(n=433)$ of them reported that they smoke, $82.0 \%(n=821)$ reported that they do not use nonprescribed medication, and 97.3\% $(n=992)$ reported that they do not use any type of drugs compared to $2.7 \%(n=17)$ who reported using these drugs. Although the percentages of non-using is small, this percentage is alarming as 27 children are risking their life when they use drugs such as marijuana and hashish and then join very long working hours.

Related to risk behaviors among school nonworking children, $5.0 \%(\mathrm{n}=102)$ of them reported that they smoke, and $14.1 \%(\mathrm{n}=288)$ of them use nonprescribed medications. The study also showed that $1.4 \%(n=26)$ of them reported using drugs such as marijuana and hashish, and this percentage, though small in terms as 
Table 2. Physical complaints in relation to children working status.

\begin{tabular}{ccccccccccc}
\hline \multirow{2}{*}{ Variable } & \multicolumn{2}{c}{ School working } & \multicolumn{2}{c}{ Nonschool working } & \multicolumn{2}{c}{ School nonworking } & Test statistics \\
\cline { 2 - 9 } & $\begin{array}{c}\text { \% within } \\
\text { group }\end{array}$ & $\mathrm{n}$ & $\begin{array}{c}\text { \% within } \\
\text { group }\end{array}$ & $\mathrm{n}$ & $\begin{array}{c}\text { \% within } \\
\text { group }\end{array}$ & $\mathrm{n}$ & $\chi^{2}$ & $\mathrm{p}$ \\
\hline Common cold & 52.9 & 474 & 51.2 & 559 & 64.1 & 1332 & 54.3 & $<0.001$ \\
Influenza & 19.5 & 175 & 27.0 & 293 & 20.2 & 419 & 20.3 & $<0.001$ \\
Checked your doctor for a health problem & 30.5 & 274 & 20.2 & 220 & 35.5 & 730 & 93.4 & $<0.001$ \\
Have you visited an emergency department & 11.8 & 106 & 12.7 & 138 & 14.3 & 295 & 3.2 & 0.37 \\
Have been admitted to the hospital, even for one night? & 6.3 & 56 & 6.0 & 65 & 7.6 & 156 & 3.7 & 0.30 \\
\hline
\end{tabular}

Table 3. Difference between working and nonworking children in physical and psychosocial health.

\begin{tabular}{|c|c|c|c|c|c|c|c|c|c|}
\hline \multirow{3}{*}{ Variables } & & \multicolumn{6}{|c|}{ Working status } & \multirow{2}{*}{\multicolumn{2}{|c|}{ Test statistics }} \\
\hline & & \multicolumn{2}{|c|}{ Nonschool working } & \multicolumn{2}{|c|}{ School working } & \multicolumn{2}{|c|}{ School nonworking } & & \\
\hline & & $\begin{array}{l}\text { \% within } \\
\text { group }\end{array}$ & $\mathrm{n}$ & $\begin{array}{l}\text { \% within } \\
\text { group }\end{array}$ & $\mathrm{n}$ & $\begin{array}{l}\text { \% within } \\
\text { group }\end{array}$ & $\mathrm{n}$ & $\chi^{2}$ & p-value \\
\hline \multirow{2}{*}{ Feeling lonely } & Never & 75.9 & 762 & 60.1 & 570 & 67.2 & 1379 & 32.1 & \multirow{2}{*}{$<0.001$} \\
\hline & Sometime to always & 24.1 & 242 & 39.9 & 378 & 32.8 & 672 & & \\
\hline \multirow[b]{2}{*}{ Feeling depressed } & Never & 73.1 & 737 & 63.5 & 554 & 77.2 & 1325 & \multirow[b]{2}{*}{24.8} & \multirow[b]{2}{*}{$<0.001$} \\
\hline & Sometime to always & 26.9 & 271 & 36.5 & 318 & 22.8 & 390 & & \\
\hline \multirow[b]{2}{*}{ Problems at home } & Never & 64.2 & 643 & 61.7 & 534 & 69.1 & 1414 & \multirow[t]{2}{*}{17.7} & \\
\hline & Sometime to always & 35.8 & 359 & 38.3 & 332 & 30.9 & 631 & & $<0.001$ \\
\hline \multirow{2}{*}{ Problems at schools/work } & Never & 76.3 & 746 & 65.4 & 573 & 73.4 & 1506 & \multirow{2}{*}{28.4} & \multirow{2}{*}{$<0.001$} \\
\hline & Sometime to always & 23.7 & 237 & 34.6 & 303 & 26.6 & 545 & & \\
\hline \multirow[b]{2}{*}{ Problems with law } & Never & 86.3 & 866 & 91.1 & 788 & 95.4 & 1936 & \multirow[b]{2}{*}{76.7} & \multirow[b]{2}{*}{$<0.001$} \\
\hline & Sometime to always & 13.7 & 137 & 8.9 & 77 & 4.6 & 94 & & \\
\hline \multirow[b]{2}{*}{ Spend times alone } & Never & 56.8 & 569 & 40.5 & 355 & 49.2 & 992 & \multirow[b]{2}{*}{50.3} & \multirow[b]{2}{*}{$<0.001$} \\
\hline & Sometime to always & 43.2 & 463 & 50.5 & 520 & 50.8 & 1022 & & \\
\hline \multirow{2}{*}{ Smoking cigarettes } & Never & 56.6 & 571 & 84.0 & 732 & 95.0 & 1932 & \multirow{2}{*}{61.4} & \multirow{2}{*}{$<0.001$} \\
\hline & Sometime to always & 43.4 & 433 & 16.0 & 139 & 5.0 & 104 & & \\
\hline \multirow{2}{*}{ Use nonprescribed medications } & Never & 82.0 & 821 & 84.6 & 735 & 85.9 & 1797 & \multirow{2}{*}{10.11} & \multirow[b]{2}{*}{0.006} \\
\hline & Sometime to always & 18.0 & 187 & 15.4 & 134 & 14.1 & 288 & & \\
\hline \multirow[b]{2}{*}{ Use drugs } & Never & 97.3 & 209 & 97.3 & 788 & 98.5 & 2061 & \multirow[b]{2}{*}{157.6 .0} & \multirow[b]{2}{*}{$<0.001$} \\
\hline & Sometime to always & 2.7 & 17 & 2.7 & 22 & 1.4 & 26 & & \\
\hline
\end{tabular}

percentage and proportion, the harmful effect of drug use makes this figure alarming for critical situation in the future.

Related to risk behaviors among school working children, the analysis showed that $16 \%$ of children reported that they smoke, of whom $8 \%$ always smoking. About $15.4 \%(n=134)$ of them use nonprescribed medication, $2.7 \%(n=22)$ did report that they have used drugs such as hashish and marijuana which is also an alarming figure among this group of children, and $16.0 \%(n=139)$ 
reported that they smoke.

\subsection{Difference between Working and Nonworking Children in Physical and Psychosocial Health}

Related to the differences between working children and nonworking children in their physical and psychosocial health (Table 3) using chi-square, the analysis showed that there is a significant difference between children in regards to feeling lonely, feeling depressed, frequency of problems at home, problems with laws, smoking status, using drugs and nonprescribed medications, and time spent alone. The greatest difference found between the children was in using drugs such as hashish and marijuana, smoking status and problems with law.

\subsection{Anger Expression}

Regarding anger expression, the analysis (see Table 4) showed that $58.9 \%(n=1232)$ of school nonworking children group, the results revealed that of these children reported that they felt like yelling at someone. About 40.1\% ( $n=839$ ) of these children felt like breaking things. Regarding the anger control, $71 \%(n=1468)$ of these children reported that they able to control their temper. In addition, $82.8 \%(n=1733)$ reported that they tried to be patient. Regarding school working children, the analysis showed that $62.6 \%(n=561)$ of them reported that they felt like yelling at someone, $45.0 \%(n=403)$ said they had a bad temper, $52.0 \%(n=466)$ reported that they slammed doors or stomped their feet when they were angry. However, 73.5\% ( $n=659)$ of these children reported they were able to control their temper. Regarding nonschool working children, the analysis showed that that 52.8\% $(n=530)$ reported that they feel angry, $65.4 \%$ $(n=666)$ got very angry if their parents or teachers criticized them. However, 80.5\% $(n=820)$ of these children reported they had been able to control their temper. Comparing working and nonworking children (using ANOVA test), the results revealed that there were statistical significant differences in total score and two of the subscales; anger trait and anger out between groups. The results revealed that the lowest mean scores of the anger trait subscale, anger out, subscale, anger in, subscale, and total score were observed among nonschool working children. The post hoc comparison showed that statistical differences were between nonschool working children and other groups, while no statistical differences found between school working and school nonworking children. However, means scores of total anger expression scale and the all subscales were higher in school working children than all other groups. This is indicated that school working children had the highest negative impact of child work.

\section{DISCUSSION}

This study is concerned about examining the physical and psychosocial health impact of child labor and comparing health status of working children at schools and at the industrial sites. Demographically, and similar to previous national studies $[5,16,17]$, the results showed that most children work to learn a skill and help their families. This makes poverty and socioeconomic circumstances as the main reasons for child labor in Jordan. This also corresponds with claims of ILO [1] that socioeconomic status and has a significant role in exacerbating the child labor phenomenon in the world. In addition, the study revealed that most children are working in the field of vehicle maintenance, services and had long working hours. This indicates that working children are working in conditions that expose them to physical risk and exhaustion and chemical hazards. The unhealthy working condition will also increase the children's vulnerability to mental and physical health deteriorations and that might be irreversible. According to Woodhead [3] the nature of the work determines the type of risk resulting from any given work. The work is considered positive if it does not affect the child's physical health and growth and does not affect his school performance. In this study, child work is definitely considered negative one as most of working children are vulnerable to various type of physical and chemical risk due to the nature of their work, and

Table 4. Mean scores of total Anger Expression Scale for Children (AESC) the subscale.

\begin{tabular}{|c|c|c|c|c|c|c|c|c|}
\hline \multirow{2}{*}{ Dimension } & \multicolumn{2}{|c|}{ Nonschool working } & \multicolumn{2}{|c|}{ School working } & \multicolumn{2}{|c|}{ School nonworking } & \multicolumn{2}{|c|}{ Test statistics } \\
\hline & Mean & SD & Mean & SD & Mean & SD & $\mathrm{F}$ & p-value \\
\hline Trait anger & 18.1 & 6.30 & 20.0 & 6.59 & 19.2 & 6.60 & 11.16 & 0.000 \\
\hline Anger out & 11.3 & 3.63 & 11.5 & 3.74 & 10.6 & 3.60 & 13.56 & 0.000 \\
\hline Anger control & 14.9 & 3.86 & 14.9 & 3.96 & 14.8 & 4.46 & 0.57 & 0.635 \\
\hline Total anger expression scale & 52.5 & 9.56 & 54.6 & 11.16 & 52.8 & 11.69 & 3.43 & 0.016 \\
\hline
\end{tabular}


long working hours.

Physically, the results revealed that nonworking school children had lower level of physical health than working ones. Also school working children had lower level of physical health than nonschool working children. School working children had higher reports of common cold and flu, and visiting physicians and emergency departments for the purpose of treatment. While the majority of nonschool working children had complained of headache, vision problems, hearing problems, and enuresis. The results are consistent with previous national studies [17] that found that working children had significant physical health problems. Nevertheless, nonworking children still had the highest reports of physical health problems which may increase the concerns about the role of school health services and socio-economic status of children.

Psychologically, the results revealed that school working children had significant psychosocial disturbances. Whereas $25 \%$ of them reported feeling lonely and depressed, $15 \%$ had also reported problems at home, work, and with law and police. Also, school working children found to have higher scores in terms of anger expression in contrast with nonschool working children. The results support previous international study reported that school and nonschool working children had more psychological disturbances than school nonworking children [18]. This may raise questions about the quality of psychological and social support available to working children at home, school and work. Working children are not given the time to live their childhood period appropriately and deprived from all possible means of psychosocial development. Children, therefore; are expected to suffer psychological and physical problem that later will deteriorate their mental and psychosocial wellness. In addition, school working children are suffering pressure of illegal working conditions that deprive them from all civil rights to health and education. As a result, school working children are deprived from health care privileges at home, school and work. Children who are supposed to receive love and care at schools and homes are struggling with problems that force them to seek other sources of support and care to compensate them for love and care deprivation. One alternative used by children in this study was their peers at schools and work. Probably this source of support was not positive as children were involved in disruptive behaviors such as smoking cigarettes and drugs. The figures of using cigarettes and drugs are alarming although seem literally small. According to Grant and Dawson [19], using substances early in life found to associate positively with early development of addiction later on life. Previous national and international studies reported that working children found to have number of risk factors that include smoking cigarettes and using narcotics $[3,5,8,9,20]$ which also has been found in this study. Therefore, the results infer that working children are isolated from their families, lack family monitoring system, deprived from sources of information, and not educated about risk related behaviors that increases their vulnerability to physical and psychosocial problems and disturbances. As mentioned above, nonschool working children had higher proportions of psychosocial problems. This makes schools and homes are not supposed to be food and shelters only and rather a prepared environment than enable growth and development. In addition, children expect from their homes and schools to provide them with appropriate education, enhancing psychological growth, promoting social relationships, developing their mental and bio-psycho-social skills and capabilities. Working children lack the power at home, school and worksite and struggle to adapt to the adulthood requirements that they are unaware of due to their developmental stage.

\section{CONCLUSION}

In conclusion, working children at school or left schools and nonworking school children suffer a number of physical and psychosocial problems and involved in number of risk behaviors. Therefore, there is a need to provide an appropriate health care for children at school through a systematic health screening and frequent checkups. There is a need to activate the role of school health professionals including school nurses to take their responsibility do perform frequent checking and follow up for children who show drop of their academic achievement, have maladaptive and low social skills. Efforts also have to be geared toward increasing awareness among families; especially those who have low socio-economic level and low level of education. The efforts should emphasize the importance of having these families allow their children pursue their education instead of sending them to workshops and industrials sites. Also there should be an emphasis on the education system and school environment. Curricula and school environment have to consider the child mental and emotional needs. Schools have to develop their teachers' capacity and skills to use appropriate teaching strategies that attract children to schools. Decision and policy makers have to consider and enhance the dialogue at school settings. Laws should also emphasize the parents' legal responsibility for their children's education. Government and community institutions should make an effort to eliminate child labor as a priority on their agendas. This requires collaboration between all parties who are concerned about the impact of child labor.

\section{ACKNOWLEDGEMENTS}

This study has been funded by the National Council for Family Affairs 
and CHF International. Amman, Jordan.

\section{REFERENCES}

[1] International Labour Organization (2008) Child labour, education and health: A review of the literature. The International Program on the Elimination of Child Labour (IPEC), Geneva.

[2] Department of Statistics (2008) National survey for child labor in Jordan 2007/2008. Directorate of Family Surveys, Amman.

[3] Woodhead, M. (2004) Psychosocial impacts of child work: A framework for research, monitoring and intervention. International Journal of Children's Right, 12, 321-377. doi:10.1163/1571818043603607

[4] Edmonds, E.V. (2007) Child labor: Discussion paper. Institute for the Study of Labor, Bonn.

[5] Gharaibeh, M. and Hoeman, S. (2003) Health hazards and risks for abuse among child labor in Jordan. Journal of Pediatric Nursing, 18, 140-147. doi:10.1053/jpdn.2003.31

[6] Saif, I. (2006) Rapid assessment of the worst form of child labor in Jordan: Survey analysis. The University of Jordan, Amman.

[7] Stegmann, K. (2003) Child health and the worst forms of child labor. Antislavery International Working Document, London.

[8] Dmour, H. (2006) Demographic, social, and economical characteristics of working children and their families and its relationship to reckless behaviors. The University of Jordan, Amman.

[9] Matalqa, H. (2004) Street children in the city of Irbid: Society study. The University of Jordan, Amman.

[10] Fekaday, D., Alem, A. and Hagglof, B.D. (2006) The prevalence of mental health problems in Ethiopian child laborers. Journal of Child Psychology \& Psychiatry, 47, 954-959. doi:10.1111/j.1469-7610.2006.01617.x
[11] Brislin, R.W. (1970) Back translation for the cross-cultural research. Journal of Cross Cultural Research, 1, 185-216. doi:10.1177/135910457000100301

[12] Chapman, D.W. and Carter, J.F. (1979) Translation procedures for cross cultural use of measurement instrument Education Evaluation and Policy Analysis, 1, 71-76.

[13] Constantino, R.E. and Bricker, P.L. (1997) Social support, stress, and depression among battered women in the judicial setting. Journal of the American Psychiatric Nurses Association, 3, 81-88.

[14] Nelson, L.R., Barnard, M.U., King, C., Hassanain, R. and Repoff, M.A. (1991) Instrument development for the determination of adolescent health needs. Journal of Adolescent Health, 12, 164. doi:10.1016/0197-0070(91)90469-3

[15] Steele, R.G., Legerski, J.-P., Nelson, T.D. and Phipps, S. (2009) Anger expression scale for children: Initial validation among healthy children and children with cancer. Journal of Pediatric Psychology, 34, 51-62. doi:10.1093/jpepsy/jsn054

[16] Department of Statistics (2007) National survey for child labor in Jordan. DOS, Amman.

[17] Al-Kayyali, G. (2006) The health effects on child laborers working in auto repair aged 10 - 16 years. Ein-Elbasha Region/Balqa Governorate, Jordan, unpublished thesis.

[18] Forastierie, V. (1997) Children at work: Health and safety risks. ILO, Geneva.

[19] Grant, B.F. and Dawson, D.A. (1997) Age at onset of alcohol use and its association with DSM-IV alcohol abuse and dependence: Results from the National Longitudinal Alcohol Epidemiologic Survey. Journal of Substance Abuse, 9, 103-110. doi:10.1016/S0899-3289(97)90009-2

[20] Tarouni, M. (2002) Poverty and child labor in Jordan: Anthropologist study. Center for strategic studies. University of Jordan, Amman. 